\title{
More than Spelling and Grammar: Students Who Prefer to Write Outperform Students Who Prefer to Present
}

\author{
Krassimir Yankulov* \\ Department Molecular and Cellular Biology, University of Guelph, Guelph, Ontario, Canada, N1G2W1 \\ *Corresponding author: yankulov@uoguelph.ca \\ Received September 03, 2014; Revised October 23, 2014; Accepted November 02, 2014
}

\begin{abstract}
Oral presentations and posters are becoming key assignments in a growing number of university courses. While the enhancement of presentation skills is highly desirable, the learning benefits of these assignments have rarely been evaluated. Here I report the learning outcomes of students who prefer a presentation assignment versus students who prefer a writing assignment. Both groups are students in a $4^{\text {th }}$ year molecular biology course. The period of analysis spans 7 years. The performance of these two cohorts (total of 393 students) has been measured by their marks in the midterm and final exams and by their engagement in class discussions. Statistical analysis of the data indicates that the writers have slightly but consistently outperformed the presenters. Considerations of teaching style variations could not explain the higher marks of the writers. These observations suggest that strong writing skills can provide a sizeable gain to overall learning skills and can enhance the overall learning outcomes.
\end{abstract}

Keywords: writing skills, university education, learning outcomes

Cite This Article: Krassimir Yankulov, "More Than Spelling and Grammar: Students Who Prefer to Write Outperform Students Who Prefer to Present.” American Journal of Educational Research, vol. 2, no. 11 (2014): 1029-1035. doi: 10.12691/education-2-11-5.

\section{Introduction}

Increasing enrollment, reduced funding and the everevolving web has put universities under pressure to cut the cost of education and to modernize teaching $[1,2,3,4]$. The Universities have responded by a diversity of distant education, MOOC (Massive Open Online Courses), blended courses and learner-centered integrated academic programs $[3,5,6,7,8]$. These include an abundance of interactive web-based tools and oral presentations and less frequently the traditional writing assignments. Besides cost reductions, these novel didactics aim to align the skills and the expectations of contemporary students with the long-standing criteria for success in learning.

Academic writing plays a critical role in higher education and has been the focus of many studies and books [9-14]. In contrast, the learning via in-class presentations has received little scrutiny. There is no question that the enhancement of presentation skills is very important in a society that increasingly relies on oral communication. In this respect, the necessity for such practice is well justified. On the other hand, the presentation assignments are often the culminating point of a case study or a learner-centered section of a course. Hence, assignments of this type are also meant to incorporate a solid pedagogical component, not just an enhancement of a skill. It is not clear how this pedagogical component compares to the traditional approach of researching and writing an essay, a review or a proposal. In a more general sense, it is not clear how presentation and writing skills contribute to learning outcomes and to the overall success in exams and competitions.

In recent years I have noticed that students in who have opted for written assignments seem to get higher overall marks in a senior molecular genetics course. I hypothesised that good writing skills enhance their overall learning abilities. I tested this hypothesis by tracking the performance of two groups of students for 7 years. These groups had a free choice of selecting a writing assignment or a presentation assignment with an equal weight (25/100) for the final mark. The learning outcomes of the two cohorts have been measured by their marks in the midterm and final exams and by the engagement in class discussions. The comparison has pointed to a minor, but statistically significant better performance of the writers of a research proposal (from now on called simply "writers") over the presenters of an original research paper (from now on called "presenters"). I discuss the implications of this observation.

\section{Materials and Methods}

In a fourth year university course (Applied Molecular Genetics, enrollment of 50-70 students per year) the students are asked to select one of two optional assignments: the writing of a research proposal or the presentation of an original research paper. The "writers" form groups of two and are asked to write a proposal on one of 3-4 topics, which are announced in the beginning of the semester. In the first half of the semester I teach the material necessary for the writing of these proposals. After 
the submission of the proposals by the writers, both the writers and presenters are asked to write a short anonymous review for 1 or 2 proposals in different years. Details on this assignment have already been published [15] and are not going to be discussed here. The "presenters" form groups of three and are given a list of 12-14 original research papers to choose from. They select one of these papers and then have at least 6 weeks to analyse it in detail, prepare a presentation and then present it in class. The class is learning from these presentations and is encouraged to asks questions and provide comments. Insightful questions and comments receive "bonus" marks. The course outline containing the specific instructions for the written and presentation assignments for 2013 is presented as Supplemental Material. Based on extensive discussions with students and on online postings, there has been no indication that the timing of the assignments or any perceived easiness of one assignment over the other was a factor in the choice of the students. Hence, it is assumed that the choice is free and reflects the preferences of the individuals.

The writing of a proposal or the presentation of a paper is worth 25 out of total 100 marks for the course. The writing of a peer review is worth 10/100 marks. A midterm exam was included in the course in 2010-2013. It covers the first half of classes and aims to provide a learning opportunity for both writers and presenters and to prepare them for the review. The midterm exam was worth 10-15/100 marks in different years. The final exam emphasises the second half of the course and the presented original research papers. On average, $50-70 \%$ of the weight in the final exam is based on the presentations and $30-50 \%$ on the accompanying lecture material provided by me. The final exam was worth 50-65/100 marks in different years. The engagement of the students in class discussions is recognised by "bonus marks", which are added to the other marks. I used the distribution of bonus marks between the two groups to assess their in-class activity.

Data on student performance in this course was collected from the 2007-2013 classes. The midterm exam, final exam and bonus marks have been downloaded from the files that have been submitted to the University Registrar. The students were sorted as "writers" and "presenters" and their identities have been removed. The raw numbers were then transferred to MS Excel ${ }^{\circledR}$ and the average marks, standard deviations and $p$-values (probability, determined by $t$-test for two samples assuming equal variances)were calculated for each year. Subsequently, all marks were pooled and re-analysed. In total, the 246 presenters and 147 writers have been included in these calculations. All calculations are shown in Table 1 and Table 2. The marks for the peer reviews have been discussed before [15] and are excluded from this study. The marks of students who have written a midterm exam, but have dropped the course and have not written a final exam, have also been excluded. Finally, the rate of failure was calculated only for students who have written and failed the final exam. Some of these students have not failed the course based on the cumulative mark that includes the assignments and the midterm.

Table 1. Average marks for the midterm and final exams. The average marks and standard deviations for the writers and the presenters were calculated for the midterm and final exam as percent values for each individual year (white boxes) and for the pooled marks for the 2007-2013 period (grey boxes). Details are provided in the text. $p$-values were calculated by the $t$-test algorithm for two samples assuming equal variances

\begin{tabular}{|c|c|c|c|c|c|}
\hline \multirow{2}{*}{ Midterm exam } & \multicolumn{2}{|c|}{ Average Mark } & \multicolumn{2}{|c|}{ Standard Deviation } & \multirow[t]{2}{*}{$p$ values } \\
\hline & presenters & writers & presenters & writers & \\
\hline 2011 & $60.7 \%$ & $72.4 \%$ & $22.2 \%$ & $12.8 \%$ & 0.0051 \\
\hline 2012 & $63.7 \%$ & $69.8 \%$ & $21.7 \%$ & $16.8 \%$ & 0.0462 \\
\hline 2013 & $73.2 \%$ & $79.7 \%$ & $16.5 \%$ & $14.0 \%$ & 0.0036 \\
\hline pooled marks & $65.9 \%(n=79)$ & $74.5 \%(n=57)$ & $20.7 \%$ & $17.0 \%$ & 0.000002 \\
\hline Final exam & presenters & writers & presenters & writers & \\
\hline 2007 & $67.8 \%$ & $71.3 \%$ & $12.14 \%$ & $12.58 \%$ & 0.1105 \\
\hline 2008 & $72.4 \%$ & $74.7 \%$ & $19.0 \%$ & $13.4 \%$ & 0.2261 \\
\hline 2009 & $62.6 \%$ & $63.7 \%$ & $17.7 \%$ & $13.9 \%$ & 0.4928 \\
\hline 2010 & $73.6 \%$ & $79.5 \%$ & $16.6 \%$ & $14.4 \%$ & 0.0484 \\
\hline 2011 & $72.0 \%$ & $79.6 \%$ & $18.8 \%$ & $11.7 \%$ & 0.0261 \\
\hline 2012 & $68.0 \%$ & $69.5 \%$ & $15.9 \%$ & $8.1 \%$ & 0.4618 \\
\hline 2013 & $75.3 \%$ & $73.1 \%$ & $16.2 \%$ & $15.1 \%$ & 0.8706 \\
\hline pooled marks & $69.3 \%(n=236)$ & $72.5 \%(n=147)$ & $16.36 \%$ & $14.99 \%$ & 0.0002 \\
\hline
\end{tabular}

Table 2. Failure rates and class participation. Class participation and failure rates for each year were calculated by dividing the sum of bonus marks or the sum of failures, respectively, by the number of students in each individual group. The average values, standard deviations and $p$ values for the 2007-2013 period are shown in the grey boxes. Details are provided in the text. $p$-values were calculated by the $t$-test algorithm for two samples assuming equal variances.

\begin{tabular}{|c|c|c|c|c|}
\hline & \multicolumn{2}{|c|}{ Fail rate } & \multicolumn{2}{|c|}{ Class participation } \\
\hline & presenters & writers & presenters & writers \\
\hline 2007 & $9.2 \%$ & $9.5 \%$ & 0.10 & 0.04 \\
\hline 2008 & $14.3 \%$ & $15.0 \%$ & 0.08 & 0.13 \\
\hline 2009 & $22.2 \%$ & $9.5 \%$ & 0.11 & 0.06 \\
\hline 2010 & $7.1 \%$ & $6.3 \%$ & 0.21 & 0.20 \\
\hline 2011 & $4.2 \%$ & $0.0 \%$ & 0.27 & 0.13 \\
\hline 2012 & $9.7 \%$ & $11.1 \%$ & 0.23 & 0.19 \\
\hline 2013 & $3.8 \%$ & $0.0 \%$ & 0.20 & 0.09 \\
\hline Average & $10.2 \%$ & $7.0 \%$ & 0.18 & 0.13 \\
\hline Standard Deviation & $7.0 \%$ & $6.1 \%$ & 0.07 & 0.06 \\
\hline$p$ values & \multicolumn{2}{|c|}{0.93671} & \multicolumn{2}{|c|}{0.96712} \\
\hline
\end{tabular}

\section{Results}

Student enrollment and marks in different years. The number of students who have taken this class varied in different years and has peaked in 2007 when the so- 
called double cohort (higher student enrollment caused by the elimination of the final year in secondary schools in the province of Ontario) entered the senior university courses. Because of the insufficient number of teaching assistants to mark the written assignments, in this year more students were encouraged to select presentations. In addition, presenter groups in this year were formed by four students. In all other years the presenter groups consisted of three students and there was no pressure whatsoever to select one or the other assignment. The writers had always formed groups of two. With the exception of 2007, the proportion of students who prefered to present rather than to write was steady at about $60 \%$ (Figure 1). The distribution of the marks in different years did not show significant deviations as exemplified by the graphs in Figure 1. These considerations pointed to a consistent enrollment and consistent student performance throughout 2007-2013 and provided a good foundation for comparison and statistical evaluation.

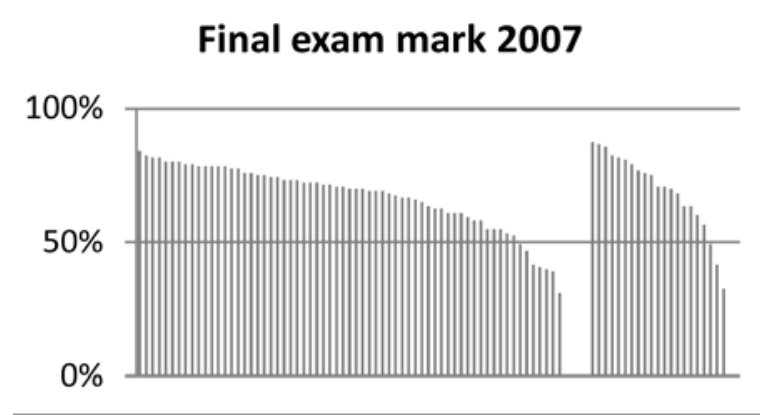

Final exam mark 2008

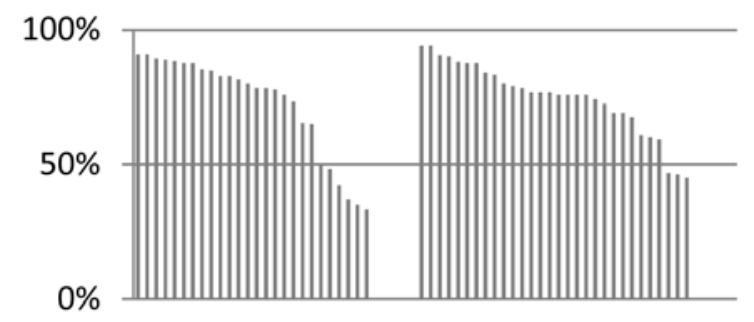

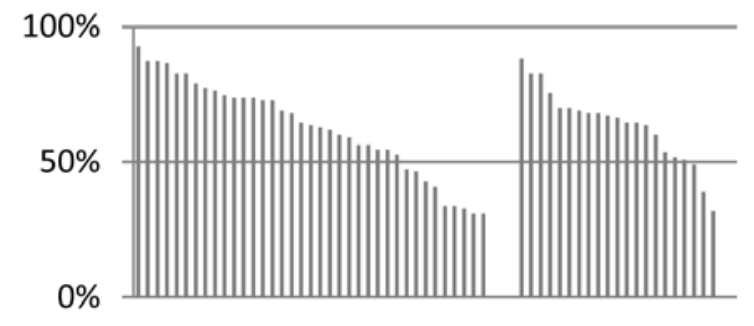
Final exam mark 2010

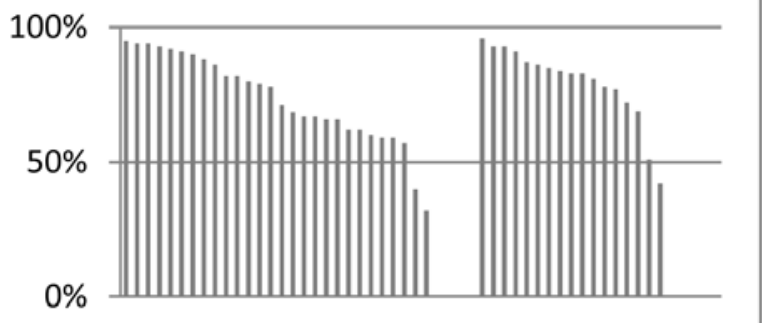

Figure 1. Distribution of the final exam marks of writers and the presenters in 2007-2013. Each bar represents a single mark. The marks from each year were grouped and separately sorted before plotting

Comparison of the performance of writers and presenters in individual years. The marks for the midterm and the final exams, the bonus marks for class participation and the number of failures at the final exam had been sorted and analyzed separately for each year of classes. The average values and the standard deviations for these criteria are plotted in Figure 2- Figure 5. The

\section{Final exam mark 2011}

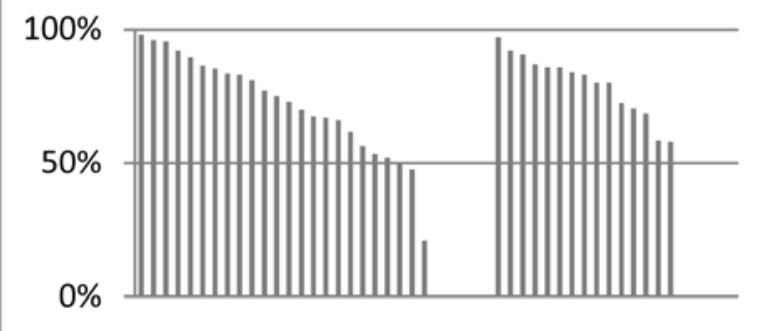

Final exam mark 2012

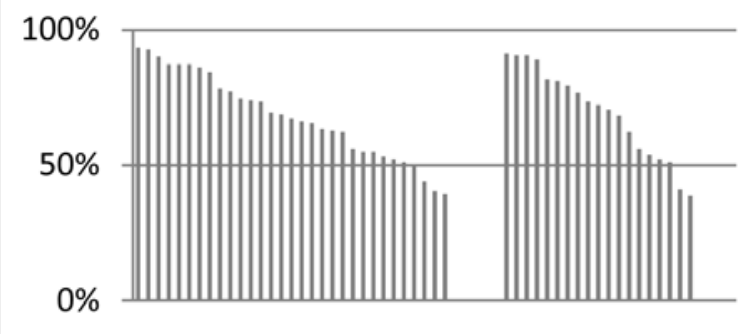

Final exam mark 2013

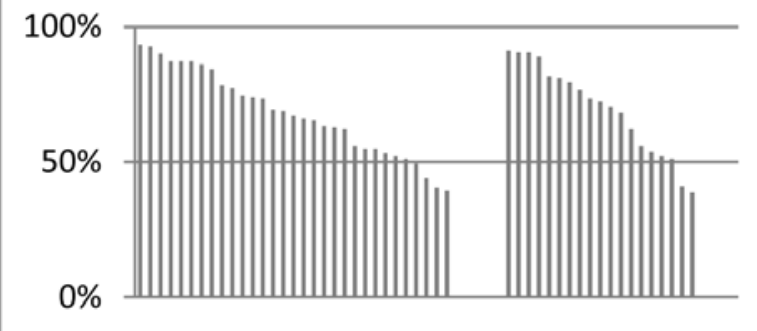

calculations and the $p$-values are provided for reference in Table 1 and Table 2.

As shown in Figure 2, in each year the writers had outperformed the presenters in the midterm exams. This exam was introduced in 2011 and the analysis was limited as compared to the other three categories. Despite the smaller data pool, in each year the calculations pointed to a statistically significant $(p<0.05)$ difference in favor of 
the writers. Similar result was observed when the data from all years were pooled. This outcome was not so surprising. It is conceivable that during the preparation for the research proposal the writers were more engaged in the learning of the course material. The presenters, albeit expected to study for this exam, could be in reality less involved. Still, the significant differences of $6-12 \%$ in favor of the writers suggested that other factors may contribute to this observation. I will comment on these later on.

\section{Average midterm marks}

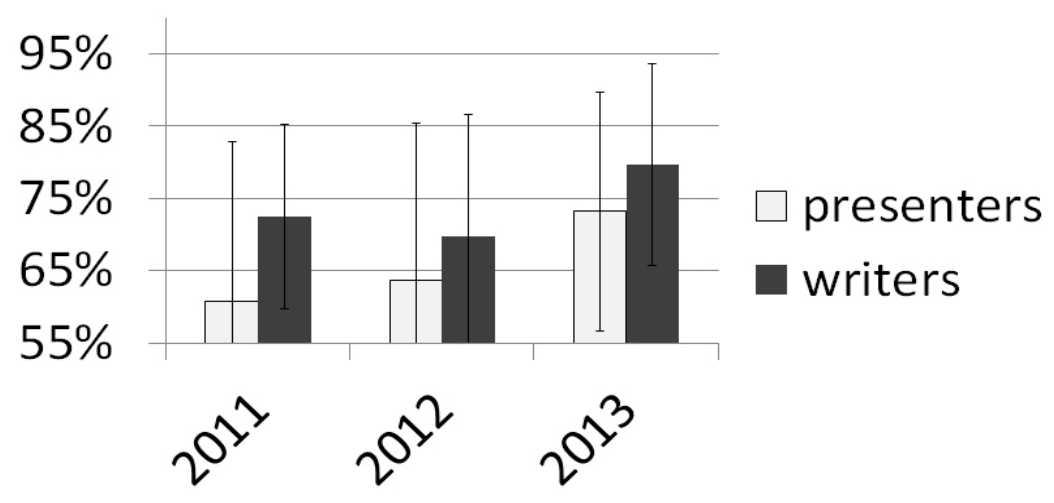

Figure 2. Average midterm marks for individual years. The midterm exam was introduced in 2011. The average marks and standard deviations for the writers and the presenters were calculated as percent values in MS Excel ${ }^{\circledR}$ and plotted

The class participation of the two groups is plotted in Figure 3. This category was gauged by the bonus marks that had been given for insightful comments or questions during presentations. These varied between 0.09 and 0.2 marks per person per semester for the different groups. The plot indicateed a somewhat higher engagement of the presenters, but the difference was statistically insignificant (Table 2, $p=0.94$ ). The situation was similar in the failure rates between the two groups. The presenters seemed to more often fail the final exam (Figure 4), but the differences were statistically insignificant (Table 2, $p=0.97$ ).

\section{Average final exam marks}

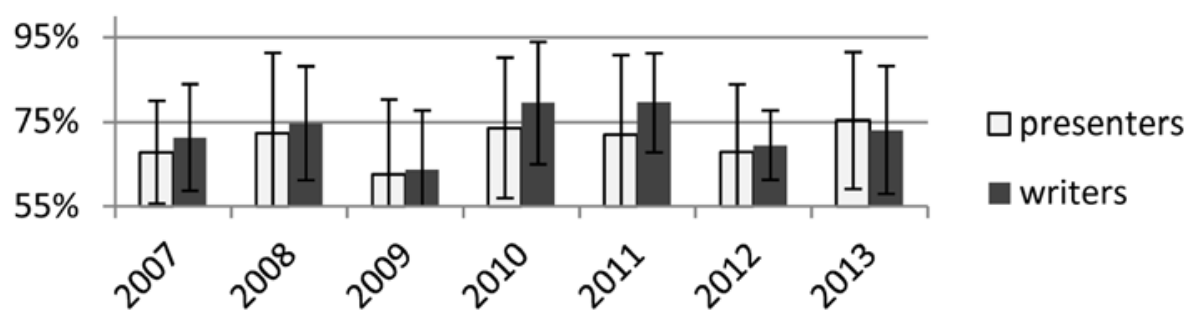

Figure 3. Class participation of the writers and the presenters. Class participation was assessed by the bonus marks that are given to students for insightful comments and questions during lectures and peer presentations. The sum of marks for each group was divided by the number of students in each group and plotted

\section{Fail rate at final exams}

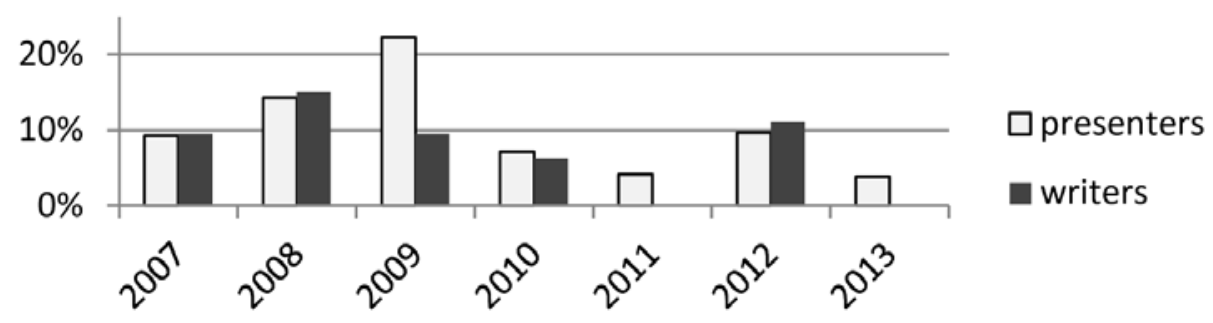

Figure 4. Failure rates at final exams for the writers and the presenters. The number of students who have failed the final exam was divided by number of students in each group and was plotted as percent values. Some of these students have not failed the course based on the cumulative mark that includes the assignments and the midterm. The sum of marks for each group was divided by the number of students in each group and plotted

Overall course performance of writers and presenters. To ensure that there was no disadvantage of the writing assignment versus the presentation assignment or vice versa, a comparison of the final exam and final cumulative marks was conducted each year. The calculations had shown no statistically significant differences in the learning outcomes between the two groups for each individual year (Table 1, p>0.05 except for 2011), but the average writer marks tended to be slightly higher as compared to the marks of the presenters 
(Figure 5). This was a surprising trend. The final exam had always emphasised the presentations in the second half of the semester and the more complex material that accompanied them. If any, this emphasis was advantageous to the presenters. In addition, the second part of the course had an intensified visual/audio instruction component that in theory could match to the preferred learning style of these students. It was this surprising trend that prompted a close look at the pooled final exam marks from 2007-2013. The cumulative course marks were not used in this analysis because they include the marks for the assignments and generate a circular argument. These calculations unveiled a 3\% difference in favor of the writers at $p<0.0005$. This solid statistical evidence tells us that the students who selected a written assignment performed better at a written exam on material that was not advantageous to them.

\section{Class participation}

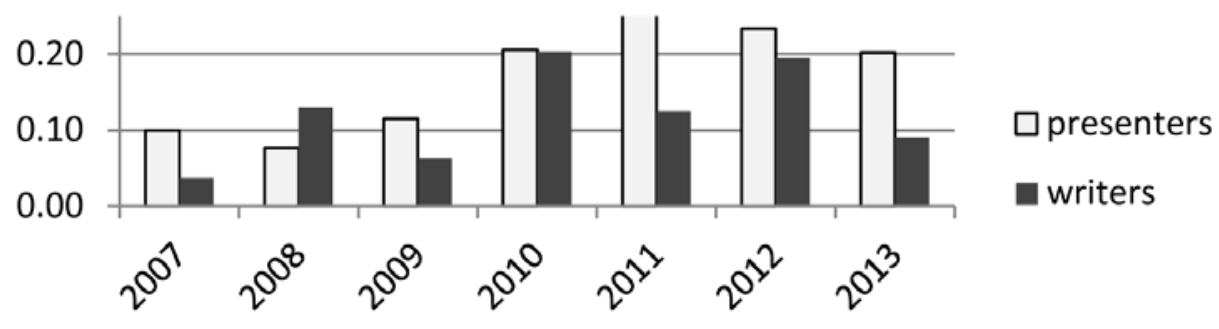

Figure 5. Average final exam marks of the writers and the presenters for individual years. The average marks and standard deviations for the writers and the presenters were calculated as percent values in MS Excel ${ }^{\circledR}$ and plotted

Can the differences between writers and presenters be explained by different teaching methods and learning styles? Learning styles occupy a special niche in the field of education [16-20]. In 2008 Pashler et al. outlined several criteria that would establish an evidencebased link between learning styles and learning outcomes [21]. The authors postulated that students with one learning style should achieve the best educational outcome when given an instructional method that differs from the instructional method producing the best outcome for students with a different learning style.

I considered the possibility that the observed difference in the performance of writers versus presenters was driven by different instructional methods and learning styles. As mentioned earlier, most of the material for the midterm was introduced through written handouts and lectures. On the other hand, most of the material for the final exam was introduced through presentations and in-class discussions. These two represented different instruction methods and could potentially impact students with different learning styles. To test this possibility, I pooled the average marks at the midterm and final exams for the two groups and plotted them in Figure 6. The diagram agrees with the projected link between learning styles and outcomes in [21] (see Figure 2 therein). It must be noted that the presumed difference in learning styles was based on speculations and this analysis should not be treated as a true factual evidence in favor of the hypotheses of Pashler et al. [21]. Nevertheless, Figure 6 supported the notion that the audio/visual-rich instruction method in second half of the course was a better match to the learning style of the presenters. It is therefore counterintuitive that students who could have been instructed in their preferred style (the presenters) underperformed as compared to students who prefer a different style (the writers). I concluded that different instruction methods and/or learning styles could not explain the differential performance of the writers and presenters.

\section{Learner style hypothesis test}

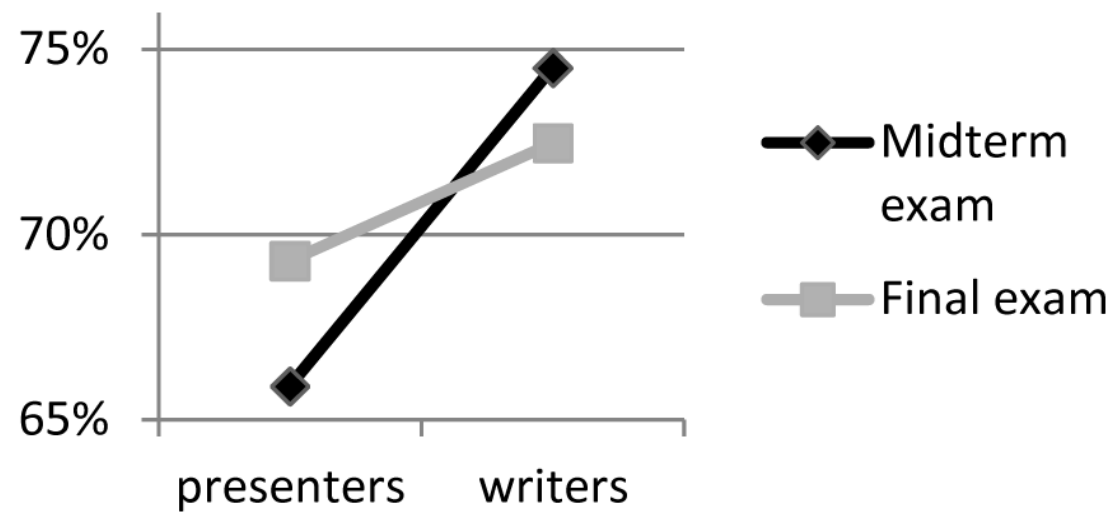

Figure 6. Test of learning style hypothesis. All marks of the presenters and writers for the 2007-2013 period were pooled and average values were calculated for the midterm and final exams. These values were plotted and connected with lines. This diagram conforms to the hypothesized outcome if a link between learning styles, teaching styles and learning outcomes exists as per [21] 


\section{Discussion}

In order to get insights into the performance of students who prefer to write or to present, I collected and statistically evaluated the marks from seven consecutive years in a senior course in genetics. The trend is apparent: the writers are slightly more successful in the final written exam. There is no indication that the instruction methods leading to this final exam give an advantage to the writers. If any, these methods would give an advantage to the presenters. Even more, the students had a free choice to select a writing or a presentation assignment and I am not aware of any comments, rumours or indications that one assignment is easier than the other. Hence, the teaching method or any perceived advantages of a given assignment are not a factor in this trend. It is still possible that my observations represent a trivial isolated exception. However, two more interesting explanations exist: the writers perform better because the exams better tune to their skills. Alternatively, they are the better learners.

The first possibility is that the writers gain their advantage because the exams match their skills and their preferred performance style. This assumption suggests that in this course there is no difference in the level of comprehension between the two groups, but the writers are more comfortable at a written exam. In this case the didactic value of the presentations and the learning styles of the students are not questioned, but the learning outcomes are. Numerous publications have dealt with the classification and the analyses of learning styles and corresponding teaching methods [16-21]. Nevertheless, the link between learning styles, teaching methods and learning outcomes is somewhat uncertain [21,22]. The analyses in this paper add to this uncertainty by suggesting that preferred performance styles need to also be considered. If the above assumptions are correct, individuals with preferred reading/writing learning and performance styles would be more successful at a written exam as compared to individuals who prefer other learning styles. Conversely, if the exam is offered in a different format the writers would have no advantage. Students need to be informed about this possibility and broader research on this topic is warranted.

The alternative explanation for the better performance of the writers is that good writing skills do really contribute to better learning. As indicated earlier, the material for the final exam in this course was taught in the supposed preferred style of the presenters. By any measure, the better performance of the writers in the final exam could not be attributed to the teaching method. Hence, the most logical explanation for this outcome is that the writers learn better. The established 3\% difference in the marks of writers versus presenters is significant enough to make the difference at national stipend competitions or for the admission at professional schools. Again, students need to be informed about this possibility. Many publications praise the value of good writing skills [9-14], but they stop short of saying that these skills boost the learning outcomes. This manuscript raises this important issue and will hopefully incite more research in this direction.

Universities are engulfed in a culture of innovation and departure from traditional forms of education $[8,23]$.
There are many good reasons to do so. However, we are still waiting to see the adequate replacement for a solid written assignment and for good writing skills. This manuscript argues that there is no replacement for these and that educators should strive to keep them in their courses.

\section{Conclusions}

This study has found that students with preferred reading/writing learning styles were more successful at a written exam as compared to individuals who prefer other learning styles. Students need to be informed about this trend. In addition, the possibility that writing skills can provide a sizeable gain to overall learning should be extensively researched by qualified educators.

\section{Acknowledgements}

The author acknowledges the superb support of Teaching Support Services at the University of Guelph for making the peer review assignment possible. This study has been supported by a Scholarship of Teaching and Learning Award (SoTL) from the University of Guelph.

\section{Competing Interests}

The author has no competing interests.

\section{Supplementary Material}

The course outline for MBG4240-Applied Molecular Genetics for 2013.

\section{References}

[1] Eric de Corte and and J.E. Fenstad, eds. From information to knowledge; from knowledge to wisdom: Challenges and changes facing higher education in the digital age. Wenner-Gren International Series. Vol. 85. Portland Press Ltd (2010).

[2] Dalton, R., Public universities left reeling by recession, Nature. 458 (7234): p. 14-5 (2009).

[3] Daradoumis, T., R. Bassi, F. Xhafa and S. Caballe, A review on massive e-learning (MOOC) design, delivery and assessment., Eighth International Conference on Parallel, Grid, Cloud and Internet Computing. p. 208-213 (2013).

[4] Brewer, C.A., and and D. Smith, Vision and Change in undergraduate biology education: a call for action., Directorate for Biological Sciences, American Association for the Advencement of Science, Washington, DC. (2011).

[5] Emanuel, E.J., MOOCs taken by educated few, Nature. 503 (7476): p. 342-342 (2013).

[6] Mackness, J., M. Waite, G. Roberts and E. Lovegrove, Learning in a Small, Task-Oriented, Connectivist MOOC: Pedagogical Issues and Implications for Higher Education, International Review of Research in Open and Distance Learning. 14 (4): p. 140-159 (2013).

[7] Waldrop, M.M., Online learning: Campus 2.0, Nature. 495(7440): p. 160-3 (2013).

[8] Cleveland-Innes, M. and H. Kanuka, Blended and online higher education: teaching and learning in a wired world., Canadian Journal of Higher Education. 43 (3): p. i-iii (2013).

[9] Lillis, T., Researching Student Learning: approaches to studying in campus-based and distance education, British Educational Research Journal. 28 (6): p. 902-903 (2002). 
[10] Lea, M. and B. Stierer, Changing academic identities in changing academic workplaces: learning from academics' everyday professional writing practices, Teaching in Higher Education. 16 (6): p. 605-616 (2011).

[11] Ganobcsik-Williams, L., Teaching Academic Writing in UK Higher Education. Theories, Practices and Models. Universities into the 21st Century. Palgrave Macmillan Ltd. (2006).

[12] Deane, M. and P. O'Neill, Writing in the Disciplines. Universities into the 21st Century. Palgrave Macmillan Ltd (2011).

[13] Borglin, G., Promoting critical thinking and academic writing skills in nurse education, in Nurse Educ Today. p. 611-3 (2012).

[14] Smith, T.G., J. Ariail, S. Richards-Slaughter and L. Kerr, Teaching professional writing in an academic health sciences center: the Writing Center model at the Medical University of South Carolina, Teach Learn Med. 23 (3): p. 298-300 (2011).

[15] Yankulov, K. and R. Couto, Peer review in class: metrics and variations in a senior course, Biochem Mol Biol Educ. 40 (3): p. 161-8 (2012).

[16] Hawk, T.F., A. Shah, Using Learning Style Instruments to Enhance Student Learning, Journal of Innovative Education. 5 (1): p. 1-19 (2007)
[17] Leite, W.L.S., M.; Shi, Y., Attempted Validation of the Scores of the VARK: Learning Styles Inventory with MultitraitMultimethod Confirmatory Factor Analysis Models, Educational and Psychological Measurement. 70 (2): p. 323-339 (2010).

[18] Coffield, F.M., D.; Hall, E.; Ecclestone, K., Learning styles and pedagogy in post-16 learning: a systematic and critical review, Learning \& Skills Research Centre: Report. p. 1-175 (2004).

[19] DiBartola, L.M., M.K. Miller and C.L. Turley, Do learning style and learning environment affect learning outcome?, J Allied Health. 30 (2): p. 112-5 (2001)

[20] Evans, C. and J.D. Vermunt, Styles, approaches, and patterns in student learning, Br J Educ Psychol. 83 (Pt 2): p. 185-95 (2013).

[21] Pashler, H.M., M.; Rohrer, D.; Bjork, R, Learning styles: Concepts and evidence, Psychological Science in the Public Interest 9: p. 105-119 (2008).

[22] Rohrer, D. and H. Pashler, Learning styles: where's the evidence?, Med Educ. 46 (7): p. 634-5 (2012).

[23] Summerlee, A.J.S., Challenge of engagement inside and outside the classroom: the future for universities, in From Information to Knowledge; from Knowledge to Wisdom, E. de Corte, Editor. p. 67-77 (2010) 